\title{
Review of Effects of "Attachment" of the Elderly on Physical and Mental Health of Old Chronic Patients
}

\author{
Yan Shunqin ${ }^{1}$ \\ ${ }^{1}$ School of Education, China West Normal University, Nanchong, China \\ Correspondence: Yan Shunqin, School of education, China West Normal University, No 1 Shi Da Road, Nanchong, \\ China. E-mail: yanshunqin@126.com
}

Received: April 25, $2015 \quad$ Accepted: May 8, $2015 \quad$ Online Published: July 2, 2015

doi:10.5430/sass.v2n2p15 URL: http://dx.doi.org/10.5430/sass.v2n2p15

\begin{abstract}
Late in life, the resources available to the aged to cope with separation, loss, especially diseases sharply decrease. The "attachment" relationship plays a very important role again. The old chronic patients have a strong demand for close relationship. The "attachment" of the elderly has great effects on the mental health and the stability and even the recovery of illnesses of the old chronic patients.
\end{abstract}

Keywords: attachment; attachment object, attachment style, old chronic patient, physical and mental health

Attachment is the strong emotional connection between an individual and the one he is close to. This concept was first proposed by Bowlby to describe the relationship between an infant or a child and its mother. Although the attachment theory was first used to explain the emotional relationship between an infant and its caregiver, Bowlby believed that "attachment plays an important role in one's whole life". Late in life, the self-efficacy weakens with the sharp decrease of the resources available to the elderly to cope with separation, loss, especially diseases. Particularly for the old chronic patients, the increase of the sense of fear and insecurity caused by chronic diseases makes their physical and mental dependence on the caregivers more and more prominent. Therefore, "attachment", again, plays a very important role in their life.

\section{Features of Attachment in Old people}

\subsection{Attachment Objects of Old people}

Investigation shows that the attachment objects of the elderly are different from those of infants. With the growth of the individual, different attachment relationship forms. The inner attachment style becomes more and more complicated, and the types of attachment objects are also diversified. The same as the young adults, the attachment objects of the elderly include their spouse, parents, friends, siblings, and so on. The difference is that the attachment style also includes their relationship between them and their adult children. In addition, Cicirelli also proposed the theory of "symbolic attachment", whose objects include the dead parents and religious figures (such as God, Buddha etc.). He believed that, in symbolic attachment, an individual establishes the representation of attachment objects, from which one obtains the sense of intimacy and security. In many of the attached objects, there is great difference in those of the elderly: Among the close objects of the home-based elderly, $56.1 \%$ are their spouse, $20.2 \%$ are the spouse and children, $21.1 \%$ are children, and $2.6 \%$ are relatives and friends. It is obvious that to the home-based elderly, the important attached object is their spouse, which proves the saying -- young couples are the company when becoming old. Marital attachment, a special and important emotional connection, becomes one of the important aspects of physical and mental health of the elderly, especially of those families with the Empty Nest elderly. The study of $\mathrm{Wu}$ Wenjia in Taiwan also shows that the long lasting marital relationship can give the elderly a relatively strong sense of security. Investigation shows that the old chronic patients who are in the first marriage with their spouse feel more support than those remarried ones do. Compared with the home-based elderly, for those living in nursing homes, $86.3 \%$ of their beloved ones are their children, and second to that are the spouse, relatives and 
friends. This may be due to the fact that most of the elderly in nursing homes are widowed, so they change the important attachment objects to their children.

\subsection{Attachment Styles of the Elderly}

The attachment of the elderly is the continuity of the early attachment. The attachment style in childhood would extend to adult life, even to the old period, through the internal mechanism developed in early social and parent-child experiences. In Bowlby's theory, the infant attachment style is divided into three types: security attachment, insecurity-avoidance attachment, and insecurity-anxiety-contradiction attachment. The attachment style of adults strongly reflects that in their childhood, which includes: avoidance attachment (hard to trust others, avoidant in displaying attachment, inclined to be or being compulsively self-reliant), attachment of anxiety and contradiction (feeling hard to know others and helpless, being more anxious in attachment relationship), security attachment (able to establish practical self-efficacy, easy to trust others, and having appropriate and controllable awareness, expression and management of the experience of depression). Study on the self-report of the elderly shows that among the elderly, the indifference attachment is the majority, about 50\%-72\%; the security attachment accounts for 30\%-40\%, and attachment of contradiction and fear accounts less. The research on elderly attachment styles shows that the division and distribution of dimensions of attachment styles differ with different measuring tools used by researchers. For example: in the average attachment styles measured by Liu Minzhen, the security attachment accounts for $69.6 \%$ of the total samples; the fear attachment is $12.5 \%$; the indifference attachment is $12.1 \%$, the attachment of possessiveness is $5.9 \%$. In the study of Wu Wenjia on the attachment styles of given relationship, the contradiction attachment accounts for $44 \%$ of the total samples, the security attachment is $39 \%$, and the refusal attachment, $17 \%$. The questionnaire on the elderly attachment compiled by scholars like Zhai Xiaoyan in mainland China includes 3 dimensions. The outcome of the study shows that of all the samples, the proportion of security attachment is the highest, followed by anxiety attachment; the least is refusal attachment. In addition, the styles and distribution of the elderly attachment correlate greatly to its different cultural background and economic status.

\section{The Problems of Physical and Mental Health Faced by Old Chronic Patients}

The senile chronic diseases increase with the increase of the old population. The main senile chronic diseases among the elderly in urban communities are hypertension, diabetes mellitus, coronary heart disease, bone and joint disease, and stroke and so on. Research shows that among the old chronic patients, more than half of them suffer one disease, and some suffer two or more diseases synchronously. The typical feature of chronic diseases is of the long course, with serious complications, which requires a long-term or even life-long dose. Therefore, those old patients suffer a lot. When coping with their Illnesses, they have some mental problems in various degrees and styles. Among them, proximately $22.7 \%$ suffer from depression, $16 \%$ suffer from anxiety and $18 \%$ suffer form compulsive refusal. Some of them feel hopeless for their illnesses, and many even suffer from neurosis. With the prolongation of the disease course, those chronic patients probably become more obstinate and dependent, and less confident and sociable. As for the family, it brings great pressure and burden to the families with old chronic patients, who need long-term care. So, they are more apt to feel guilty to their families, especially to the long-term caregivers. Some even feel abandoned, with the manifestation that they hope to be understood and cared, but they behave with investigation and refusal, and show their emotions like complaints, rage, alienation, loneliness, and silence and so on.

\section{Effects of "Attachment of the Elderly" on Physical and Mental health of Old Chronic Patients}

According to the attachment theory, being ill is an apparent stress event to the patient. In this situation, the attachment system of the patient will be activated. To those old chronic patients, the activation of "attachment system" plays an important role again. Study shows that there's great difference among old chronic patients with different attachment styles in experiencing emotional loneliness and social loneliness: Patients with security attachment seldom feel emotionally lonely or socially lonely. They have more positive emotional expressions even when being ill; but old people with indifferent attachment style often have both the two feelings; the elderly with refusal style shows more negative emotions in illness; the score of the subjective well-being of the old chronic patients with security attachment style is higher than that of those with the style of avoidance and fear; the old women with insecurity attachment style feel relatively less happy in such aspects as society, psychology, and materials. According to the survey of the author, the old chronic patients with security attachment style differ greatly from those with refusal style in the prevalence of depression and coping strategies. Moreover, there's certain correlation between different attachment styles and the stability as well as the prevention of further deterioration of 
chronic diseases. This manifests the situation that the stability of the illness of the old people with security attachment style is significantly different from that of those with anxiety or refusal styles. The old chronic patients with security attachment style behave positively in their life and interpersonal communication. They can establish good social relations, and have effective communication with their loved ones and friends, which has important effects on the stability and the remission of chronic diseases, and contrarily, the disease will relapse or even become worse. It is thus clear that the "attachment" of the elderly is of great effects on both physical and mental health of the old chronic patients.

\section{Countermeasures}

From the effects of the attachment of the elderly on the physical and mental health of old chronic patients, it can be seen that these are important ways that we establish a secure attachment style for old chronic patients and equip them with more attachable objects in order to cope with the physical and mental health of the increasing old chronic patients. It can be started from the following aspects: Firstly, from the point of view of the old chronic patients, direct psychological intervention can be implemented on them in that a good state of mind is an important element in the remission of their illnesses, which can be achieved through regular examination on chronic diseases carried out in communities, hospitals and colleges for seniors, and through lectures about physical and mental health of the aged and targeted group counseling for those old chronic patients with serious mental problem. Through the above measures, we can help the old chronic patients to know about their own illnesses, and meanwhile to improve their ability to manage their diseases and cope with their life. What's more important is that we should try to encourage old people to express their need for close relationships in community activities and help them to keep a healthy attachment with the attached objects. In addition, group activities can increase mutual communication and support between the old chronic patients, all of these external supplements can, to a certain extent, expand the attachable objects of the elderly. Meanwhile, benignant interaction can also promote the adjustment and change of the elderly attachment style. Secondly, from the point view of the important attached objects of the old chronic patients, attention should be given to the physical and mental condition of their long-term caregivers. In Chinese culture, the concepts of "the old company", "the provision for the old" are important spiritual support for old people. "The attachment of the elderly and the care in chronic diseases" is one of the important subjects in the study of the psychological function in the attachment of the elderly. Study shows that children's security attachment to their parents is strongly related to their future care behavior--the stronger the attachment relationship is, the less burdened they feel in care giving. The attachment style of the spousal caregivers manifests differently when they are facing the diseases of their spouse. The anxious attached individual shows panic and negation towards the illness of the spouse, while the caregivers in security attachment can easily cope with the challenge of the deterioration of the illness and are qualified in taking care of their ill spouse. Therefore, in the process of care and company, the understanding, support, and care from the important attached objects of old chronic patients can significantly promote the mental health as well as the stability and recovery of the old chronic patients.

\section{Conclusion and Prospect}

At present, wide attention is paid to the study on the effects of the "attachment" of the elderly on physical and mental health of old chronic patients. Nevertheless, empirical research and intervention strategies are being explored. The elderly are faced with chronic diseases in the process of aging and with multi-challenges brought by loss of function on both physical and mental health. It is the research direction to seek for effective ways of measuring on attachment of the elderly and to add longitudinal and cross cultural studies. To sum up, the study of the effects of elderly attachment on their physical and mental health is of important theoretical and practical significance for old chronic patients themselves, their families and the society.

\section{Acknowledgements}

This paper is the research findings of the youth research project supported by China West Normal University in 2013, with the subject -- research on the effects of attachment in old adulthood on the mental health of old chronic patients and spousal caregivers in communities. (Project No: 13D055. Project director: Yan Shunqin) 


\section{References}

Ai Juan, \& Zhang Min. (2012). Study on the Relationship between the elderly loneliness, Suicide attitude and attachment style. Chinese Health Psychology Journal of China Psychological Health, 20(6), 830-833.

Chen Yu, Yu Wenbo, \& Jiang Jingchuan. (2014). Research on Distribution Pattern of Old People's Attachment and Its Relationship with Parent-Child Support. Science of social psychology, 9, 49-56.

Deng Yunlong, Yang Zhonghua, \& Chen Xiangyi. (2012). The Correlation between Social Support and Family Function and Subjective Sense of Happiness of the Elderly. Journal of Chinese Gerontology, 8, 3501-3503.

Diehl M., Elnick A B., Bourbeasu L S., et al. (1998). Adult attachmentstyles: Their relations to family context and personality. Journal of Personality and Social Psychology, 74(6), 1656-1669.

Jia Lina, Yuan Ping, Zhuang Hailin et al. (2011). Present Situation of Senile Chronic Diseases and Its Relationship with Quality of Life. Public Health in China, 27(11), 1361-1364.

Jo"rn von Wietersheim, \& Henrik Kessler. (2006). Psychotherapy with Chronic Inflamm- matory Bowel Disease Patients: A Review. CLINICAL REVIEW, 12, 1175-1184.

Li Biefei, Xie Xiumei, \& Yu Guolong. (2008). Analysis on Mental Health of Old Chronic Patients. Journal of Modern Medicine in China, 13(18), 73-75.

Li Chunhua, Wang Dahua, \& Chen Cuiling. (2008). Features of Attachment in the Elderly. Progress in Psychological Science, 16(1), 77-83.

Li Tao, Wang Tingzhao, \& Xu Guangxing. (2010). Research on adult attachment and its characteristics. Statistics and Information Forum, 9(9), 104-107.

Li Tonggui. (2006). Overview of Several Hot Issues in Attachment Theory. Journal of Peking University (NATURAL SCIENCE EDITION), 42(1), 18-25.

Liu Hang, Liu Xiuli, \& Li Yue. (2012). Characteristics of Attachment in the Elderly. Journal of Chinese Gerontology, 12(24), 5624-5626.

Magai C., Cohen C., Milburn N, et al. (2001). Attachment styles in older European-American and African-American Adults. Journal of Gerontology, B Psychol Sci Soc Sci, 56B, 1, S28-S35.

Pan Jie. (2009). Different Attachment Styles, Social Support and Subjective Sense of Happiness of the Elderly. Jiangxi Normal University.

Webster J. D. (1997). Attachment style and well-being in elderly adults:A preliminary investigation. Canadian Journal on Aging, 16(1), 101-111.

Zhai Xiaoyan, Li Chunhua, Wei Hong et al.. (2010). Designing of Questionnaires on Old Couple's Attachment, Psychological Development and Education, 2, 199-204. 